\title{
Renal tubular dysfunction in patients with inflammatory bowel disease treated with aminosalicylate
}

\author{
S Schreiber, J Hämling, E Zehnter, S Howaldt, W Daerr, A Raedler, W Kruis
}

\begin{abstract}
Background-An increasing number of case reports indicate potential nephrotoxicity of 5-aminosalicylic acid (5-ASA), which shares similarities with the chemical structures of both phenacetin and acetylsalicylic acid.

Aim-In a point prevalence study the occurrence of sensitive indices indicative of early kidney malfunction was assessed in outpatients with inflammatory bowel disease.

Methods-Routine indices of kidney function (creatinine clearance, urinary protein content, $\mathrm{pH}$, electrolytes, and microscopy) were investigated in 223 patients with inflammatory bowel disease as well as sensitive markers of glomerular or tubular dysfunction (microproteinuria by SDS polyacrylamide gel electrophoresis (SDS-PAGE), urinary concentrations of $\mathbf{N}$-acetyl- $\boldsymbol{\beta}-\mathrm{D}$-glucosaminidase, $\alpha 1$-microglobulin, $\gamma$-glutamyltransferase (GGT), alkaline phosphatase (AP), and albumin). Histories of exposure to 5-ASA were assessed by questionnaire.

Results-Patients receiving high amounts of 5-ASA, both actual as well as on a lifetime basis, showed an increased prevalence of tubular proteinuria by SDSPAGE. Raised values for urinary AP and GGT indicate proximal tubular epithelial cells as the source. All other kidney function tests were normal. Analysis of covariates indicated strong associations between disease activity and size of 5-ASA doses as well as alterations in kidney tubular function.

Conclusion-The possibility exists that high doses of 5-ASA may be associated with proximal tubular proteinuria. This point prevalence study cannot dissect the possible impact of chronic inflammation from high dose 5-ASA treatment and further prospective studies are warranted.
\end{abstract}

(Gut 1997; 40: 761-766)

Keywords: 5-aminosalicylic acid, 4-aminosalicylic acid, sulphasalazine, inflammatory bowel disease, nephrotoxicity.

Aminosalicylate compounds are widely used in both acute phase and remission maintenance treatment of inflammatory bowel disease. Considerations of long term toxicity seem important as lifetime maintenance treatment is usually recommended for ulcerative colitis. ${ }^{1-3}$ Both acetylsalicylic acid and phenacetin, which have been implicated in the occurrence of nonsteroidal anti-inflammatory drug (NSAID) induced nephropathy, share structural similarities with 5-ASA. ${ }^{4-6}$ In addition, one study has indicated that 5-ASA may cause lesions to kidney tubular epithelial cells in both rats and dogs when fed in high doses. ${ }^{7}$ Studies by Mahmud et al, which were conducted in parallel with the work presented here, indicate that patients with inflammatory bowel disease treated with 5-ASA show an increased renal leakage of albumin, as detected by sensitive techniques. $^{89}$ These studies also suggested that microalbuminuria in patients with inflammatory bowel disease may be activity related because a correlation with increased serum tumour necrosis factor- $\alpha$ (TNF- $\alpha$ ) concentrations was seen. ${ }^{9}$ No clinically relevant long term nephrotoxicity has so far been reported due to chronic sulphasalazine (SASP) or mesalazine treatment. ${ }^{10}$ The introduction of mesalazine (5-aminosalicylic acid, 5-ASA) in different pharmaceutical formulations into the treatment of patients with inflammatory bowel disease has offered the opportunity of increasing dosages much further than had been possible with sulphonamide carrier compounds such as sulphasalazine. ${ }^{11}{ }^{14}$ However, systemic absorption and plasma concentrations of 5-ASA delivered from SASP were found to be lower than from equivalent doses of delayed or slow release mesalazine formulations. ${ }^{15-17}$ The potential for dose related chronic nephrotoxicity caused by long term use of mesalazines may therefore be further enhanced. We have conducted a point prevalence study using sensitive indices of renal tubular and glomerular function to assess the occurrence of altered kidney function in aminosalicylate (SASP or mesalazine) treated patients with inflammatory bowel disease.

\section{Methods}

A point prevalence study was performed with individuals selected from consecutive patients attending the Universities of Hamburg and Cologne inflammatory bowel disease outpatient clinics.

\section{ENTRY CRITERIA}

Patients with a confirmed diagnosis of Crohn's disease or ulcerative colitis of at least six months duration were included. Salicylate 
treatment had to be unchanged in the past two months preceding the study. Only patients receiving a delayed release mesalazine formulation, SASP, or no treatment were selected. Including patients on slow release mesalazine or olsalazine would have generated subgroups with small patient numbers. Concomitant treatment with corticosteroids was allowed. The maximum age was set at 60 years. Childbirth or lactation less than six months previously were exclusion criteria as well as abdominal or other major operations less than six months earlier, pre-existing renal disease (any history of renal disease dating back further than the diagnosis of inflammatory bowel disease), hypertension, diabetes mellitus, or a history of chronic ingestion of analgesics. All patients having received cytotoxic drugs (methotrexate, azathioprine), cyclosporine A, or any experimental treatment for inflammatory bowel disease within the six months preceding selection were excluded as well. Patients were also excluded who had signs of urinary tract infection by microscopy which could be confirmed by culture.

PATIENTS

A total of 223 patients out of 497 screened were entered into the study (93 with ulcerative colitis, 130 with Crohn's disease). Reasons for exclusion of 252 patients were previous use of immunosuppressive drugs or immunomudulators (61), previous experimental treatment (49), slow release mesalazine or olsalazine treatment (43), non-compliance in collecting urine or giving plasma samples (26), unwillingness to participate in the study (19), major operations (19), age $>60$ (15), signs of urinary tract infections (17), history of arterial hypertension (10), chronic use of NSAID analgesics (9), diabetes mellitus (2), pregnancy/childbirth (2), preexisting renal disease (2). Mean duration of disease was 58.3 (range 12-132) months with a mean of 3.3 (range 1-17) acute relapses. Patients were grouped into those receiving no 5-ASA, those receiving up to $1.5 \mathrm{~g} /$ day, more than 1.5 but less than $3.0 \mathrm{~g} / \mathrm{day}$, and those receiving $3.0 \mathrm{~g} /$ day or more. In patients treated with SASP the amount of 5-ASA contained in the molecule was calculated for evaluation. No differences in disease characteristics, disease activity, or sex were seen between patients younger than than 30 and those aged 30 or older. Moreover, differences in disease characteristics (location, Crohn's disease $v$ ulcerative colitis, presence of extra intestinal manifestations) between different treatment groups did not reach significance.

PATIENT DATA COLLECTION

Information on previous exposure to 5-ASA containing drugs, other drugs used for the treatment of inflammatory bowel disease, and non-steroidal analgesic drugs was obtained by a questionnaire, which was administered by the physician to the patient. To improve the accuracy of these data, the patients' medical history (prescription records) was checked whenever possible. Disease activity scores were calculated from diary cards which were filled in by the patients during the week preceding and the week after analysis of urine. Patients recorded the occurrence of specific symptoms used to calculate the Crohn's disease activity index ${ }^{1819}$ or the clinical colitis activity index..$^{20}$ The Crohn's disease activity index ${ }^{18}{ }^{19}$ provides a calculated composite score which incorporates eight items: number of liquid or very soft stools, general wellbeing, abdominal pain, abdominal mass, relative packed red blood cell volume, body weight, extraintestinal manifestations, use of opiate receptor stimulating drugs for the control of diarrhoea. Higher scores indicate more disease activity. Patients with a score below 150 are considered to be in clinical remission. Scores above 450 reflect severely active Crohn's disease. The clinical colitis activity index ${ }^{20}$ incorporates seven clinical items: number of stools, blood in stools, investigator's global assessment of symptomatic state, body temperature due to colitis, abdominal pain, extraintestinal manifestations, and erythrocyte sedimentation rate. Patients with a clinical colitis activity index $\leq 4$ are considered to be in remission. ${ }^{20}$

\section{ANALYTICAL TECHNIQUES}

All chemicals were obtained from Sigma (Munich, Germany) if not stated otherwise. Morning urine was collected and an aliquot immediately frozen. In addition, most patients collected 24 hour urine during the next day. An aliquot was taken and frozen for determination of enzyme activity. The morning urine was subjected to protein analysis by sodium dodecyl sulphate polyacrylamide gel electrophoresis (SDS-PAGE) as described by Pesce $e t$ $a l^{21}$ and Schiwara et $a .^{22}$ The analysis of microproteinuria by SDS-PAGE allows the differentiation between glomerular and tubular proteinuria by protein size and pattern. The detection of significant amounts of protein with a tubular pattern, which represents proteins originating from the tubular epithelium, was considered a pathological finding. ${ }^{2122}$ The lower sensitivity limit for urinary protein detection and analysis by SDS-PAGE was 5 $\mathrm{mg} / \mathrm{l}$, the reference range was between 7 and 56 $\mathrm{mg} / 24 \mathrm{~h}$ (90\% confidence interval). $\alpha 1$-Microglobulin ( $\alpha 1-M G)$ and albumin concentrations were determined by nephelometry and the activities of $\mathrm{N}$-acetyl- $\beta$-D-glucosaminidase (NAG), $\gamma$-glutamyl-transferase (GGT), and alkaline phosphatase (AP) by their respective enzyme activities in 24 hour urine (Boehringer Mannheim, Mannheim, Germany). To eliminate errors in 24 hour urine sampling a gradient between enzyme activity and creatinine concentration was calculated. ${ }^{23} 24$ Normal values in healthy volunteers have been obtained by Scherberich et al. ${ }^{25}$

\section{STATISTICS}

The Mann-Whitney $U$ test was carried out to evaluate differences between groups. ${ }^{26}$ Analysis 
of variance (ANOVA) or multiple cross table analysis was used to test for significance between 5-ASA exposure and prevalence of tubular proteinuria. All values are given as mean (SEM) if not indicated otherwise. Significance of differences was assumed at $\mathrm{p}<0 \cdot 05$.

\section{Results}

TREATMENTS

The Table shows 5-ASA doses taken and population characteristics of the patients with inflammatory bowel disease. Forty two per cent of patients received $\geq 3.0 \mathrm{~g} 5-\mathrm{ASA} /$ day, $8 \%$ between $1.5 \mathrm{~g} /$ day and $3.0 \mathrm{~g} /$ day, and $32.6 \%$ a maximum of $1.5 \mathrm{~g} /$ day. The remaining $(17 \%)$ patients received no 5-ASA during the two months preceding the study. Active disease was related to higher 5-ASA dosages $(p<0.0001$, Table). Average duration of disease was $58 \cdot 3$ (range 12-132) months with an average of 3.3 (range 1-17) acute relapses. Mean duration of 5-ASA treatment was found to be 32 months.

PREVALENCE OF TUBULAR PROTEINURIA AND RAISED URINE ALKALINE PHOSPHATASE CONCENTRATIONS

Proteinuria of tubular origin detected by SDSPAGE is a pathological finding. In our patient population an increase in prevalence of tubular proteinuria was seen with increasing daily dose of oral 5-ASA (Fig 1, p=0.0086). The parallel increased prevalence of raised urinary AP concentrations $\left(>0.9 \mathrm{U} / \mathrm{mmol}\right.$ creatinine, ${ }^{23}{ }^{24}$ $\mathrm{p}=0.001$ ), which coincided highly significantly with the detection of a tubular protein pattern $(p<0.0001)$, indicated that the origin of urinary proteins was most likely from the proximal tubular epithelial cells (Fig 1). Eleven per cent of patients receiving no 5-ASA treatment showed a tubular proteinuria by SDS-PAGE and $5 \%$ had raised urinary AP concentrations. Disease activity, defined by the Crohn's disease activity index or the colitis activity index, was explored as an alternative variable of either primary importance or as a confounder of altered renal function indices. The detection of tubular proteinuria by SDS-PAGE was more often seen in active disease (39 of 51 patients with a positive SDS-PAGE had active disease, $\mathrm{p}<0.0001$ ) as well as a raised urinary AP excretion (38 active out of 44 patients, $\mathrm{p}<0.0001)$. In active patients with inflammatory bowel disease $43 \%(51 / 91)$ showed a

Population characteristics

\begin{tabular}{llllll}
\hline 5-ASA treatment & None & $\leqslant 1.5$ g/day & $\begin{array}{c}>1.5 \mathrm{~g} \text { and } \\
<3.0 \mathrm{~g} / \text { day }\end{array}$ & $\geqslant 3.0 \mathrm{~g} /$ day & Total \\
\hline Patients/group & 38 & 72 & 18 & 95 & 223 \\
UC/CD & $7 / 31$ & $46 / 26$ & $8 / 10$ & $32 / 63$ & $93 / 130$ \\
Active patients & $3 / 38$ & $8 / 72$ & $8 / 18$ & $72 / 95$ & $91 / 223$ \\
Male/Female & $21 / 17$ & $30 / 42$ & $10 / 8$ & $44 / 51$ & $105 / 118$ \\
Weight (kg) (mean (SD)) & $66(10 \cdot 4)$ & $64(9 \cdot 2)$ & $63(7 \cdot 4)$ & $62(8.8)$ & $63(9 \cdot 2)$ \\
\hline
\end{tabular}

220 Patients were examined out of 497 screened.

${ }^{\star}$ Crohn's disease activity index $>150$; colitis activity index $>4$. These were obtained from diaries completed by the patients one week before and the week after urinary analysis. As expected patients with active disease received larger daily doses of 5-ASA than patients with inactive inflammatory bowel disease $(\mathrm{p}<0 \cdot 0001)$. UC=Ulcerative colitis; $C D=C$ rohn's disease.

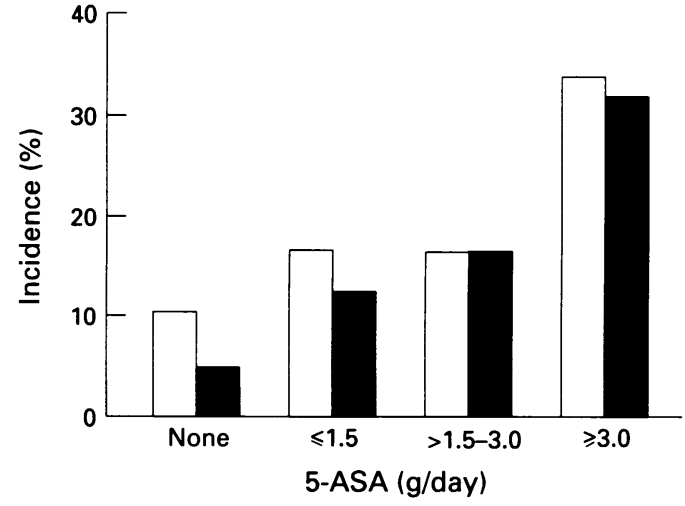

Figure 1: Point prevalence of tubular proteinuria and increased urine alkaline phosphatase $(A P)$ concentrations under 5-ASA treatment. The prevalence of tubular proteinuria (open bars, $p=0.0086$ ) as well as of increased urinary $A P$ activity ( $>0.9 \mathrm{U} / \mathrm{mmol}$ creatinine, grey bars, $p=0.001$ ) increases with daily dosages of 5- $A S A$. Interestingly, $11 \%$ of patients with inflammatory bowel disease who did not receive any 5-ASA in the two month period preceeding the study showed tubular proteinuria and $5 \%$ had an increased AP activity in urine. All $p$ values were calculated for comparison between the $\geq 3.0$ g/day group and the group receiving no 5-ASA.

tubular proteinuria detected by SDS-PAGE in comparison with $9 \cdot 1 \%$ in inactive patients (12/132). The height of clinical disease activity score was not found to correlate with the occurrence of either a pathological SDS-PAGE result or raised urinary $\mathrm{AP}$ concentrations. Serum soluble interleukin-2 receptor concentrations correlated with disease activity, but no statistical relation with the occurrence of tubular proteinuria or raised urinary AP concentrations was seen (data not shown). Unfortunately, the influence of disease activity (active disease $v$ remission) could not be statistically separated from 5-ASA dosages because of a highly significant relation between activity variables and 5-ASA doses $(p<0.0001)$ both for patients with ulcerative colitis or Crohn's disease. Differences between ulcerative colitis and Crohn's disease or between different groups (disease location and extent, previous resections) did not reach statistical significance.

URINARY ALKALINE PHOSPHATASE AND $\gamma$-GLUTAMYLTRANSFERASE ACTIVITIES

Both AP and GGT are sensitive markers of damage to the proximal tubular epithelium of the kidney. The results are expressed as marker/creatinine concentrations to standardise for differences in timing and amount of the urine collection. We found a dose dependent increase in urinary AP and GGT activities with increasing 5-ASA load with differences from normal controls reaching significance in the group of patients receiving $\geq 3.0 \mathrm{~g} 5$-ASA/day (Fig 2). The data suggest that AP values are increased much further above normal than GGT values.

ROUTINE KIDNEY FUNCTION INDICES

Excretion rates of total protein, albumin, NAG, and $\alpha-M G$ were investigated. No statistical differences were seen between different 


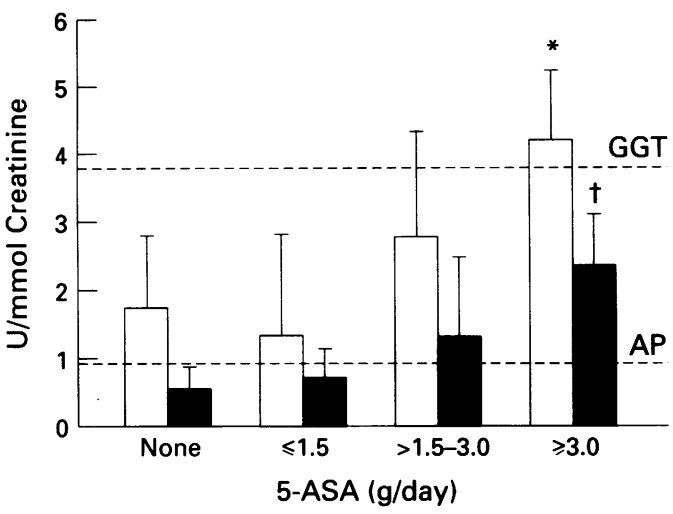

Figure 2: Urinary alkaline phosphatase $(A P)$ and $\gamma$-glutamyltransferase (GGT) activity in patients with inflammatory bowel disease with 5-ASA treatment. Urinary activities of GGT (open bars) and AP (grey bars) are shown. Values have been related to urinary creatinine excretion to compensate for sampling errors. High daily dosages of 5- $A S A$ are related to increased activities of $G G T$ $\left({ }^{\star} p<0.05\right)$ and $A P(\dagger p<0.02)$. Dotted lines show upper
normal ranges for $G G T$ and $A P$ urinary activities. ${ }^{23} 24$

treatment groups or normal controls and patients with inflammatory bowel disease treated with 5-ASA. Creatinine clearance and $\mathrm{pH}$ values were very variable, and again no statistical differences were seen between normal controls and different 5-ASA treatment groups. No correlation was seen between creatinine clearance and either cumulative lifetime dose or daily dose of 5-ASA (data not shown).

\section{CUMULATIVE 5-ASA EXPOSURE AND TUBULAR} PROTEINURIA

Cumulative 5-ASA exposure was assessed by a questionnaire. Lifetime exposure rates to 5-ASA seemed to be related $(p<0.01)$ to an increased prevalence of tubular membrane protein excretion (Fig 3). No significant correlation could be established between AP or GGT values and lifetime 5-ASA dosage. Moreover, no correlation was seen between cumulative dose and creatinine clearance, NAG values, total protein excretion, albumin excretion, and $\alpha 1-M G$ values.

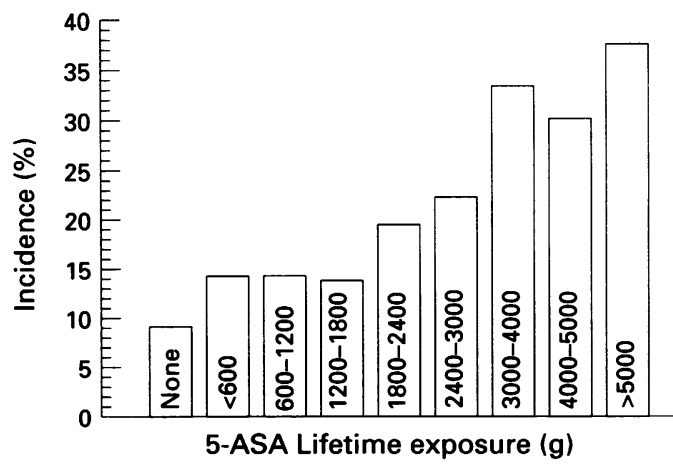

Figure 3: Point prevalence of tubular proteinuria in relation to lifetime 5-ASA intake. Point prevalence of tubular proteinuria is related to the lifetime intake of 5-ASA $(p<0.01)$. Interestingly a tubular proteinuria is also seen in $9 \%$ of patients with inflammatory bowel disease who had never received 5-ASA in their lives. The prevalence of proteinuria with a tubular pattern in the SDS-PAGE is less than $1 \%$ in the control population (data not shown).

\section{Discussion}

Acute salicylate induced tubular nephrotoxicity has been seen in patients taking aspirin overdoses or large doses of sodium salicylate. ${ }^{4}$ It is debated whether chronic analgesic nephropathy, which is associated with consumption of large amounts of phenacetin, is associated with salicylate intake as well. ${ }^{27}$ Moreover, 4aminosalicylic acid (4-ASA), a structurally related molecule which has been used for the treatment of tuberculosis over many years in high systemic doses, did not generate a chronic clinical problem with drug induced nephrotoxicity. ${ }^{28}$ In high doses, however, case reports indicate acute nephrotoxicity, in particular in patients with pre-existing renal damage. ${ }^{28} 29$ The evidence for 5-ASA or sulphasalazine (SASP) induced clinically relevant renal toxicity is rare. In rats and dogs, high doses of 5-ASA (far beyond those used in human treatment) were capable of inducing acute tubular and papillary necrosis when given over six to 12 months, ${ }^{7}{ }^{30}$ whereas a four week treatment did not induce any changes. ${ }^{31}$

In this study we have assessed sensitive indices of renal function such as classification of microproteinuria by SDS-PAGE to detect early signs of tubular dysfunction. In a point prevalence study in 223 patients with inflammatory bowel disease we found an increased prevalence of tubular membrane protein excretion, which was related to both 5-ASA dose and disease activity. The detectable excretion of tubular membrane proteins - confirmed by increased AP activity to originate most likely from proximal tubular epithelial cells - is pathological. It often precedes the clinical manifestation of chronic drug induced damage to the kidney. ${ }^{38} 39$ This study confirms the earlier work by Zehnter et al, which was conducted in fewer patients. Zehnter et al reported that a pathological SDS-PAGE showing tubular proteinuria was found only in patients treated with 5-ASA, but not in patients with inflammatory bowel disease receiving no aminosalicylates. Moreover, the authors also found raised urinary AP and GGT concentrations indicating the proximal tubular epithelium as the source of urinary protein excretion. ${ }^{40}$ Riley et al described a group of patients with quiescent ulcerative colitis, in whom renal dysfunction marker excretion values were above the 95th percentile for healthy volunteers, thereby raising the possibility of mild glomerular and tubular dysfunction in these patients. ${ }^{10}$ Recent studies have confirmed the presence of alterations of sensitive markers of renal dysfunction in patients with inflammatory bowel disease, although no relation between aminosalicylate dose, or extent or duration of disease was seen. 894142

Moreover, abnormalities in renal function tests were seen also in non-aminosalicylate treated patients ${ }^{41}$ and an influence of immunological disease activity on sensitive indices of renal function was suggested. ${ }^{9}$ Recently, renal lesions resulting in signs of tubular dysfunction were proposed to be an extraintestinal manifestation of inflammatory bowel disease. ${ }^{43}$ In a point prevalence study like the one 
presented here no clear distinction between the influence of disease activity and drug treatment can be made, if increased dosage of the antiinflammatory drug used correlates highly with disease activity. The data presented by us may therefore be indicative of either a drug induced, dose dependent or an inflammation induced, time dependent process capable of impacting on kidney function in the long term. High doses of 5-ASA may contribute to the signs of kidney tubule dysfunction seen in the study. However, $11 \%$ of non-5-ASA treated patients with inflammatory bowel disease were also excreting tubular proteins. Inflammatory mediators, including $\mathrm{TNF}-\alpha$, which are increased in inflammatory bowel disease, ${ }^{44-50}$ may play an important part in inducing tubular dysfunction. ${ }^{9}$ Our study confirms the data presented by Riley et $a l^{10}$ as well as others that NAG, $\alpha 1-M G$, creatinine clearance, albumin, and total protein excretion as well as routine kidney function indices are not raised in aminosalicylate treated quiescent patients with inflammatory bowel disease. These markers, as well as routine kidney function indices, which have been obtained as safety indices in remission maintenance studies using 5-ASA containing drugs, ${ }^{11-51}$ may be too insensitive to detect early signs of tubular damage. ${ }^{5253}$ Moreover, the negative study by Riley et al ${ }^{10}$ investigated patients with quiescent ulcerative colitis. Tubular dysfunction, however, may be related to both disease activity and drug.

A recent series of case reports indicate that acute renal toxicity may occur in humans with both SASP and 5-ASA treatment, in particular with delayed release mesalazine formulations. Clinical presentations have been typically with acute renal failure, acute nephritis, or nephrotic syndrome. ${ }^{32}$ Renal biopsies usually show signs of tubulointerstitial nephritis. ${ }^{33} 3454$ Although most case reports indicate reversibility after cessation of the drug, in some cases permanent clinical kidney dysfunction has been reported. ${ }^{33} 3554$ In all cases submitted to the pharmaceutical manufacturers ${ }^{36}$ acute renal damage was reported independent of dosage and treatment duration. Therefore, recent case reports may reflect acute allergic events rather than chronic toxicity. This hypothesis is supported by a case report in which rechallenge with both sulphasalazine and mesalazine drugs has been undertaken and in which a dose independent relapse of haematuria was found. ${ }^{37}$ The recent case reports of acute tubulointerstitial damage caused by aminosalicylates therefore most likely reflect a different pathophysiology than the findings reported in this study. The cases of acute renal failure associated with aminosalicylate therapy may describe a dose independent allergic condition, which may represent a clinical entity different from the findings reported in this study. Further prospective studies are warranted to dissect the potential influence of disease activity from 5-ASA treatment on renal tubular dysfunction. In particular the prospective evaluation of long term use of aminosalicylate drugs with different absorption kinetics (slow release mesalazine formulations
(Pentasa), double molecules (olsalazinedipentum, SASP, balsalazide), and delayed release mesalazines (Salofalk, Claversal, Asacol)) may be of importance in dissecting the influence of a systemic load with 5-ASA from that of intestinal inflammation. Particular care should be taken in monitoring renal function indices (creatinine) in patients when further increasing long term 5-ASA dosages for treatment. However, at present no clinical data have been presented suggesting that chronic treatment with aminosalicylates is unsafe unless a hypersensitivity reaction occurs.

Parts of this work have been presented at the 95th annual meeting of the American Gastroenterological Association, 1994 New Orleans, LA, USA.

We thank Dr J Armbrecht from SmithKline Beecham GmbH (Germany), C Oerns from Pharmacia A/S (Sweden), D Tauschel from Dr Falk Pharma GmbH (Germany), and Dr M Larak from Ferring GmbH (Germany) for the helpful discussion of our findings. The (Germany) for the helpful discussion of our findings. The contribution of detailed human toxicology and drug toxicity/side effect reports by SmithKlin Beecham (Germany/United Kingdom) and Pharmacia
(Sweden) is gratefully acknowledged. Parts of this work have (Sweden) is gratefully acknowledged. Parts of this work have
been supported by a grant of the Deutsche Forschungsgemeinschaft (DFG Schr 512/1-2).

1 Dissanayake AS, Truelove SC. A controlled therapeutic trial of long-term maintenance treatment of ulcerative colitis with sulphasalazine. Gut 1973; 14: 923-6.

2 Sachar DB. Maintenance therapy in ulcerative colitis and Crohn's disease. F Clin Gastroenterol 1995; 20: 117-22

3 Hanauer SB, D'Haens G. Medical management of ulcerative colitis. In: Targan SR, Shanahan F, eds. Inflammatory bowel disease: from bench to bedside. Inflammatory bowel disease: from bench to

4 Eknoyan G. Analgesic nephropathy and renal papillary nercrosis. Semin Neprol 1984; 4: 65-76.

5 Dubach UC, Rosner B, Pfister E. Epidemiologic study of abuse of analgesic containing phenacetin. Renal morbidity and mortality (1986-79). N Engl f Med 1983 308: $357-62$

6 Clive DM, Stoff JS. Renal syndroms associated with nonsteroidal antiinflammatory drugs. $N$ Engl f Med 1984; 310: 563-72

7 Calder IC, Funder CC, Green CR, Ham KN, Tange JD. Nephrotoxicity lesion from 5-aminosalicylic acid. $B M \mathcal{F}$ 1972; i: $152-4$.

8 Mahmud N, O'Connell MA, Stinson J, Goggins MG, Weir DG, Kelleher D. Tumour necrosis factor- $\alpha$ and microalbuminuria in patients with inflammatory bowe disease. Eur F Gastroenterol Hepatol 1995; 7: 215-9.

9 Mahmud N, Stinson J, O'Connell MA, Mantle TJ, Keeling $\mathrm{PW}$, Feely J, et al. Microalbuminuria in inflammatory bowel disease. Gut 1994; 35: 1599-604.

10 Riley SA, Lloyd DR, Mani V. Tests of renal function in patients with quiescent colitis: effects of drug treatment. Gut 1992; 33: 1348-52.

11 Singleton JW, Hanauer SB, Gitnick GL, Peppercorn MA, Robinson MG, Wruble LD, Krawitt EL. Mesalamine capsules for the treatment of active Crohn's disease: capsules for the treatment of active Crohn's disease: Group. Gastroenterology 1993; 104: 1293-301.

12 Hanauer SB, Krawitt EL, Robinson M, Rick GG, Safdi MA, Alpert E, et al. Long-term management of Crohn's disease with mesalamine capsules Pentasa ${ }^{\mathrm{R}}$. Am $\mathscr{f}$ Gastroenterol 1993; 88: 1343-51

13 Miner P, Hanauer S, Robinson M, Schwartz J, Arora S, Briggs RL, et al. Safety and efficacy of controlled-release mesalamine for maintenance of remission in ulcerative colitis. Dig Dis Sci 1995; 40: 296-304.

14 Sutherland LR, Martin F, Bailey RJ, Fedorak R, Dallaire C, Rossman R, et al. 5-Aminosalalicylic acid Pentasa in the maintenance of remission in Crohn's disease [abstract]. Gastroenterology 1995; 108: A924.

15 Rasmussen SN, Bondesen S, Hvidberg EF, Hansen SH Binder V, Halskov S, Flachs H. 5-Aminosalicylic acid in a slow release preparation: bioavailability, plasma leve and excretion in humans. Gastroenterology 1982; 83: 1062-70.

16 Christensen LA, Fallingborg J, Abildgaard K, Jacobsen BA Sanchez G, Hansen SH, et al. Topical and systemic availability of 5-aminosalicylate: comparisons of three controlled release formulations in man. Aliment Pharmaco Ther 1990; 4: 523-33.

17 Laursen S, Stockholm M, Bukhave K, Rask-Madsen J, Lauritsen K. Disposition of 5-aminosalicylic acid by olsalazine and three mesalazine preparations in patients with ulcerative colitis: comparison of intraluminal patients with ulcrative colonic 1990; 31: 1271-6.

18 Best WR, Becktel JM, Singleton JW, Kern F Jr. Development of a Crohn's disease activity index. National Cooperative Crohn's Disease Study. Gastroenterology 1976; 70: 439-44. 
19 Best WR, Becktel JM, Singleton JW. Rederived values of the eight coefficients of the Crohn's disease activity index CDAI. Gastroenterology 1979; 77: 843-6.

20 Rachmilewitz D. Coated mesalazine 5-aminosalicylic acid versus sulphasalazine in the treatment of active ulcerative colitis: a randomized trial. BMF 1989 ; 298: $82-6$.

21 Pesce AJ, Boreisha V, Pollack E. Rapid differentiation of glomerular and tubular proteinuria by SDS-polyacrylamide gel electrophoresis. Clin Chim Acta 1972; 7 ; 27-34.

22 Schiwara HW, Hebell T, Kirchherr H, Postel W, Weser J, Görg A. Ultrathinlayer sodium dodecyl sulfate-
polyacrylamide gel electrophoresis and silver staining of urinary proteins. Electrophoresis 1986; 7: 496-505.

23 Schwab SJ, Christensen RL, Dougherty K, Klahr S Quantitation of proteinuria by the use of protein-to creatinine ratios in single urine samples. Arch Intern Med 1987; 147: 943-4

24 Lemann J, Doumas BT. Proteinuria in health and disease assessed by measuring the urinary protein/creatinine ratio. Clin Chem 1987; 33: 297-9.

25 Scherberich JE, Mondorf WA. Beurteilung der Nephrotoxizität von Pharmaka über die Ausscheidung tubulusspezifischer Membranantigene und Enzyme. Zeitschrift für spezifischer Membranantigene und Enzyme.
die gesamte Innere Medizin 1983; 38: 571-80.

26 Sachs L. Angewandte Statistik. 7th ed. Heidelberg: Springer, 1992

27 Eknoyan G. Chronic tubulointerstitial nephropathies. In: Schrier RW, Gottschalk CW eds. Diseases of the kidney. Toronto: Little Brown, 1988: 2191-221.

28 Goodman LS, Gilman A. The pharmacological basis of therapeutics. New York: MacMillan, 1975: 1202-4.

29 Brander L, Kulback B, Niemiste M, Riska N. The effect of massive doses of PAS on renal function and electrolyte balance. Scand f Lab Clin Med 1963; 15: 38.

30 Bilyard KG, Joseph EC, Metcalf R. Mesalazine: an overview of key preclinical studies. Scand $\mathcal{f}$ Gastroenterol Suppl of key preclinical

31 Diener U, Tuczek HV, Fischer C, Maier K, Klotz U. Renal function was not impaired by treatment with 5 -aminosalicylic acid in rats and man. Naunyn Schmiedebergs Arch Pharmacol 1984; 326: 278-82

32 Novis BH, Korzets Z, Chen P, Bernheim J. Nephrotic syndrome after treatment with 5-aminosalicylic acid. BMF 1988; 296: 1442

33 Ruf-Ballauf W, Hofstädter F, Krentz K. Akute interstitielle Nephritis durch 5-Aminosalizylsäure. Internist (Berl) 1984; 30: 262-4.

34 Mehta RP. Acute interstitial nephritis. Can Med Assoc $\mathcal{f}$ 1990; 143: 1031-2.

35 Brezin JH, Katz SM, Schwartz AB, Chinitz JL. Reversible renal failure and nephrotic syndrom associated with nonsteroidal anti-inflammatory drugs. $N$ Engl $\mathcal{f}$ Med 1979 301: $1271-3$

36 Data on file reviewed by the authors: SmithKline Beecham $\mathrm{GmbH}$, United Kingdom and Germany, Pharmacia A/B, Sweden, Dr Falk Pharma GmbH, Germany and Ferring GmbH, Germany.

37 Von Mühlendahl KE. Nephritis durch 5-Aminosalizylsäure. Dtsch Med Wochenschr 1989; 114: 236.

38 Dubach UC, Schmid U. Diagnostic significance of enzymes and proteins in urine. Current Problems in Clinical Biochemistry. Vol 9. Bern: Huber Publishers, 1979.
39 Lockwood TD, Bosmann HB. The use of urinary N-acetyl$\beta$-glucosaminidase in human renal toxicology. II. Elevation of human excretion after aspirin and sodium salicylate. Toxicol Appl Pharmacol 1979; 49: 337-45.

40 Zehnter E, Dörhöfer H, Ziegenhagen DJ, Scheurlen C, Baldamus CA, Kruis W. Renal damage in patients with inflammatory bowel disease treated with 5-aminosalicylic acid and sulphasalazine [abstract]. Gastroenterologv 1991; 100: A264.

41 Bonnet J, Lemann M, Prunat A, Eugène M, Chopin N, Modigliani R. Renal function in patients with inflammatory bowel disease IBD on long-term mesalazine $\mathrm{Mz}$ or olsalazine $\mathrm{Oz}$ [abstract]. Gastroenterology 1995; 108: A786.

42 Sninsky C, Hanauer S, Powers B, Robinson M, Mayle J, Elson C, et al. Sensitive markers of renal dysfunction are elevated in chronic ulcerative colitis CUC [abstract]. Gastroenterology 1995; 108: A919.

43 Kreisel W, Wolf LM, Grotz W, Grieshaber M. Renal tubular damage: an extraintestinal manifestation of chronic inflammatory bowel disease. Eur $\mathcal{f}$ Gastroenterol Hepatol inflammatory b: 461-8.

44 Mahida YR, Wu K, Jewell DP. Enhanced production of interleukin $1-\beta$ by mononuclear cells isolated from mucosa with active ulcerative colitis or Crohn's disease. Gut 1989; 30: $835-8$.

45 MacDonald TT, Hutchings P, Choy MY, Murch S, Cooke A. Tumour necrosis factor- $\alpha$ and interferon- $\gamma$ production measured at the single cell level in normal and inflamed human intestine. Clin Exp Immunol 1990; 81: 301-5.

46 Raedler A, Steffen M, Reinecker C, Witthoeft Th, Schreiber $S$, MacDermott RP. Lamina propria mononuclear cells in patients with inflammatory bowel disease secrete enhanced levels of IL-1 $\beta$, TNF- $\alpha$ and IL-6 [abstract]. Gastroenterology 1992;102: A681.

47 Stevens C, Walz G, Singaram C, Lipman ML, Zanker B, Muggia A, et al. Tumor necrosis factor- $\alpha$, interleukin- $1 \beta$ and interleukin 6 expression in inflammatory bowel disease. Dig Dis Sci 1992; 37: 818-26.

48 Schreiber S, Raedler A, Conn AF, Rombeau JL, MacDermott RP. Increased release of soluble interleukin2 receptor by colonic lamina propria mononuclear cells in inflammatory bowel disease. Gut 1992; 32: 236-9

49 Isaacs KL, Sartor RB, Haskill S. Cytokine messenger RNA profiles in inflammatory bowel disease mucosa detected by polymerase chain reaction amplification. Gastroenterology 1992; 103: 1587-95.

50 Schreiber S, Heinig T, Thiele HG, Raedler A. Immunoregulatory role of interleukin 10 in patients with inflammatory bowel disease. Gastroenterology 1995; 108: 1434-44.

51 Singleton JW, Law DH, Kelley ML, Mekhjiam HS, Sturdevant RAL. National cooperative Crohn's disease study: adverse reactions to study drugs. Gastroenterologv' 1979; 77: 870-82.

52 Gabriel R. Time to scrap creatinine clearance? BMF 1986; 293: $1119-20$

53 Payne RB. Creatinine clearance: a redundant clinical investigation. Ann Clin Biochem 1986; 23: 243-50.

54 Hämling J, Raedler A, Helmchen U, Schreiber S. 5-ASA associated renal tubular acidosis with decreased renal function in Crohn's disease. Digestion 1997; in press. 